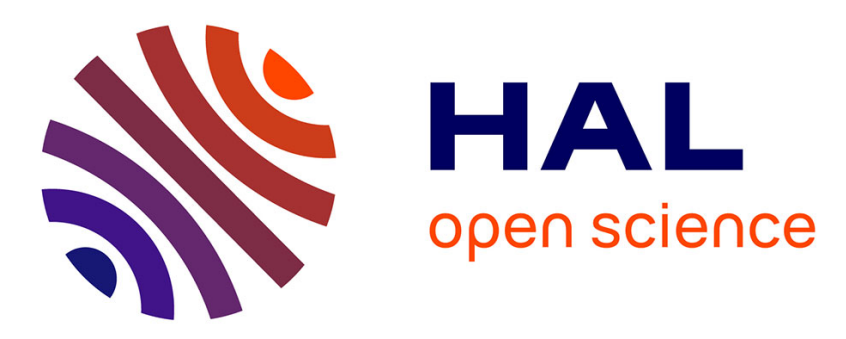

\title{
Nurse-patient interaction and communication: A systematic literature review
}

Steffen Fleischer, Almuth Berg, Markus Zimmermann, Kathleen Wüste, Johann Behrens

\section{- To cite this version:}

Steffen Fleischer, Almuth Berg, Markus Zimmermann, Kathleen Wüste, Johann Behrens. Nursepatient interaction and communication: A systematic literature review. Journal of Public Health, 2009, 17 (5), pp.339-353. 10.1007/s10389-008-0238-1 . hal-00535269

\section{HAL Id: hal-00535269 \\ https://hal.science/hal-00535269}

Submitted on 11 Nov 2010

HAL is a multi-disciplinary open access archive for the deposit and dissemination of scientific research documents, whether they are published or not. The documents may come from teaching and research institutions in France or abroad, or from public or private research centers.
L'archive ouverte pluridisciplinaire HAL, est destinée au dépôt et à la diffusion de documents scientifiques de niveau recherche, publiés ou non, émanant des établissements d'enseignement et de recherche français ou étrangers, des laboratoires publics ou privés. 


\title{
Nurse-patient interaction and communication: A systematic literature review
}

\author{
Steffen Fleischer • Almuth Berg • \\ Markus Zimmermann • Kathleen Wüste • \\ Johann Behrens
}

Received: 21 July 2008 / Accepted: 14 November 2008 / Published online: 6 January 2009

(C) Springer-Verlag 2008

\begin{abstract}
Aim The purpose of this review is to describe the use and definitions of the concepts of nurse-patient interaction and nurse-patient communication in nursing literature. Furthermore, empirical findings of nurse-patient communication research will be presented, and applied theories will be shown.

Method An integrative literature search was executed. The total number of relevant citations found was 97 . The search results were reviewed, and key points were extracted in a standardized form. Extracts were then qualitatively summarized according to relevant aspects and categories for the review.

Results The relation of interaction and communication is not clearly defined in nursing literature. Often the terms are used interchangeably or synonymously, and a clear theoretical definition is avoided or rather implicit. Symbolic interactionism and classic sender-receiver models were by far the most referred to models. Compared to the use of theories of adjacent sciences, the use of original nursing theories related to communication is rather infrequent. The articles that try to clarify the relation of both concepts see communication as a special or subtype of interaction.

The main intention of communication and interaction in the health setting is to influence the patient's health status or state of well-being. Identified important structural factors of communication were: role allocation, different use of language and registers, and the nursing setting. The process
\end{abstract}

S. Fleischer $(\triangle) \cdot$ A. Berg $\cdot$ M. Zimmermann $\cdot$ K. Wüste $\cdot$

J. Behrens

Institute of Health and Nursing Sciences,

Martin-Luther University Halle-Wittenberg,

Magdeburger Strasse 8,

06097 Halle, Germany

e-mail: steffen.fleischer@medizin.uni-halle.de of communication is often described with a phase model; communication often happens during other interventions and tasks. In general, influencing factors can be organized into the categories of provider variables, patient variables, environmental and situational variables.

Conclusion The included citations all conclude that communication skills can be learned to a certain degree. Involvement of patients and their role in communication often is neglected by authors. Considering the mutual nature of communication, patients' share in conversation should be taken more into consideration than it has been until now. Nursing science has to integrate its own theories of nursing care with theories of communication and interaction from other scientific disciplines like sociology.

Keywords Nurse-patient interaction · Nurse-patient communication $\cdot$ Nurse-patient relation $\cdot$ Literature review

\section{Background}

The importance of communication and interaction for nursing has been an often stated point by nurses and nursing scientists since Florence Nightingale in the 19th century and continuing until today. Approaches and methods to describe or investigate the phenomenon of nurse-patient interaction and communication vary. As professionals spending the most time with patients and nursing home residents, nurses ultimately hold a position of obvious importance in the health-care team to satisfy the communication needs of patients.

There is a long tradition of research dealing with the interaction between health professionals and clients. Basic work was done on the communication between physicians and patients by Parsons (1968), dealing with the role expectations 
and the interaction process. Later Ruesch and Bateson (1995) as well as the description of communication between medical practitioners and patients as "observing the body" by Niklas Luhmann (1993) resumed these investigations.

The generation of nursing-related knowledge and theory is an important goal of nursing science. From the theorist's perspective, the extent of concepts and theories of adjacent scientific disciplines and the use of proprietary theories in nursing literature are of interest. Existing literature reviews on communication mainly lack an overview of the theoretical backgrounds used by the included publications (Mathews 1983; May 1990; Shattell 2004) and were restricted to a more linguistic perspective (Walther 2003) or to certain patient groups (Canales 1997; Caris-Verhallen et al. 1997).

To judge the status of theory and knowledge generation in nursing sciences in the field of nurse-patient communication, it is important to review not only empirical findings, but also the use of concepts and theories in nursing literature. This review follows these trails for the professional communication in the field of nursing and caring.

\section{Purpose}

The purpose of this review is to investigate two aspects in the nursing literature on nurse-patient communication and interaction.

First, the utilization and definitions of the concepts of nurse-patient interaction and nurse-patient communication in nursing literature will be investigated and the theoretical backgrounds of the included articles will be described.

Second, empirical findings and normative statements about how communication and interaction in the nursing setting happen and what factors influence the process of nurse-patient communication and interaction as they are described in nursing literature will be presented.

Interaction and communication of interest in this review will not be interaction or communication among nurses or different professions in health care. Likewise, the interaction/ communication between nurses and familiar relatives of the patient or resident will not be presented in this review. Additionally, to communication and interaction, the concept of nurse-patient relationship in nursing literature will be investigated as well as the question how far it is influenced or determined by nurse-patient communication and interaction.

\section{Method}

An integrative literature search was executed using the databases of MEDLINE, CINAHL, and library catalogues. Different combinations of the search terms interaction, communication, nursing, care, and nurse-patient relation- ship were used. The search was limited to publications in English and German. There was no restriction to publication types in the search process.

There were no limitations regarding the time period of publication. Literature search was done in September 2008.

Found citations were sorted out based on their abstracts using the following exclusion criteria: educational programs in the case of the evaluation of theme-centered curricula or supervision; nurse-physician relation; nurse-relative relation; mother-child relation; pediatric nursing; midwifery-care; use of communication technology in nursing situations (e.g. telecare); communication and interaction problems with foreign patients; communication in means of therapy; linguistic studies. Citations with specific medical diagnoses as well as certain phases of dementia or patient states on ICU and endof-life nursing were excluded. This was done to get a more general impression of communication and interaction.

The search results were reviewed, and key points were extracted in a standardized form. Extracts were then qualitatively summarized according to relevant aspects and categories for the review.

Categories of the form were: definition of interaction and communication, relation of interaction and communication, theoretical background of communication and interaction concepts, investigated patient group and setting, structures of interaction, and finally research design.

\section{Results}

Description of the search results

The total number of citations found relevant after the application of exclusion criteria was 97. They are listed in Table 1, sorted according to used methods. Qualitative methods were by far used most frequently $(n=35)$, followed by quantitative methods $(n=24)$. Secondary research $(n=$ 12) included qualitative reviews about communication/ interaction and nurse-patient relationships. No quantitative review was identified. Seven articles proposed or developed methods to investigate communication or interaction. Twenty-two articles were included that presented nonresearch literature, namely essays, theoretical comments, or guidelines without empirical basis.

The research focus of most articles was mainly descriptive, as can be seen in Table 2. Hospitals and nursing homes were the prevailing settings in which communication and interaction were researched (Table 3).

Theoretical background and definitions of basic terms

One aim of this review was to illustrate the definitions of communication and interaction used in nursing literature 
Table 1 Used research methods

\begin{tabular}{|c|c|c|}
\hline \multicolumn{3}{|c|}{ Used quantitative methods } \\
\hline \multicolumn{2}{|l|}{$\mathrm{RCT}$} & Burgio et al. 2000; Diers et al. 1972 \\
\hline \multicolumn{2}{|c|}{ Nonrandomized-controlled study } & Aguilera 1967 \\
\hline \multirow[t]{9}{*}{ Descriptive research } & Survey & $\begin{array}{l}\text { Anderson 1979; Bourhis et al. 1989; Larsson and Starrin 1990; Loveridge and } \\
\text { Heineken 1988; Park and Song 2005; Ruan and Lambert } 2008\end{array}$ \\
\hline & Standardized observation & Dean et al. 1982; Salyer and Stuart 1985 \\
\hline & Standardized observation and questionnaire & Armstrong-Esther and Browne 1986; McCann and McKenna 1993 \\
\hline & Standardized observation and interviews & Schröck 2003 (Review of Altschul 1972) \\
\hline & Quantitative evaluation of video recordings & Caris-Verhallen et al. 1998; Caris-Verhallen et al. 1999b \\
\hline & $\begin{array}{l}\text { Quantitative evaluation of video recordings and } \\
\text { questionnaires }\end{array}$ & Caris-Verhallen et al. 1999a \\
\hline & $\begin{array}{l}\text { Quantitative evaluation of audio tapes and } \\
\text { standardized observation }\end{array}$ & Jones and van Amelsvoort Jones 1986 \\
\hline & Quantitative evaluation of transcribed conversations & Edberg et al. 1995; Moore and Kuipers 1992; Williams et al. 2005a \\
\hline & Standardized rating of simulated cases & Gilbert 1998; Hollinger and Buschmann 1993 \\
\hline \multicolumn{2}{|c|}{ Pre-test/post-test design without control } & Allen and Turner 1991 \\
\hline \multicolumn{3}{|c|}{ Used qualitative methods } \\
\hline \multicolumn{2}{|l|}{ Grounded theory } & $\begin{array}{l}\text { Dornheim 2003; Hewison 1995a; Hewison 1995b; Martin and Barkan 1989; } \\
\text { McCutcheon and Pincombe 2001; Rundell 1991; Schiereck } 2000\end{array}$ \\
\hline \multicolumn{2}{|l|}{ Ethnography } & Barrere 2007; Breeze and Repper 1998; Fosbinder 1994; Millard etal. 2006 \\
\hline \multirow{10}{*}{$\begin{array}{l}\text { Qualitative } \\
\text { evaluation of ... }\end{array}$} & Group discussions (focus groups) & Aranda and Street 1999; Kaakinen et al. 2001; Sheldon et al. 2006 \\
\hline & Interviews & $\begin{array}{l}\text { Cleary and Edwards 1999; Cleary et al. 1999; Koeniger-Donohue 2007; Usher } \\
\text { and Monkley 2001; Westin and Danielson } 2007\end{array}$ \\
\hline & Interviews and participating observation & Graneheim et al. 2001; Vivian and Wilcox 2000 \\
\hline & Interviews and non-participating observation & Schröck 2003 (Review of Altschul 1972) \\
\hline & Video recordings & $\begin{array}{l}\text { Daubenmire et al. 1978; Hansebo and Kihlgren 2002; Kettunen et al. 2002; } \\
\text { Routasalo and Isola 1998; Spiers } 2002\end{array}$ \\
\hline & Video recordings with simulated patients & Williams and Gossett 2001 \\
\hline & The participators'study diaries & Wikström 2003 \\
\hline & Transcribed audio tapes & Edberg et al. 1995 \\
\hline & $\begin{array}{l}\text { Personal journals, group discussions, follow-up } \\
\text { indepth interviews and field notes }\end{array}$ & Tuckett 2007 \\
\hline & Participant observation & Berg et al. 2007 \\
\hline \multicolumn{2}{|c|}{ Qualitative-heuristic method } & Darmann 2000 \\
\hline \multicolumn{2}{|l|}{ Case studies } & Goode 2004; Heineken 1998 \\
\hline \multicolumn{3}{|c|}{ Secondary research } \\
\hline \multicolumn{2}{|l|}{ Qualitative reviews } & $\begin{array}{l}\text { Canales 1997; Caris-Verhallen et al. 1997; Mathews 1983; May 1990; O'Kelly } \\
\text { 1998; Routasalo 1999; Shattell 2004; Tacke 1999; Tuckett 2005; Turnock 1991; } \\
\text { Walther 2003; Williams } 2001\end{array}$ \\
\hline \multicolumn{3}{|c|}{ Proposed/developed methods } \\
\hline \multicolumn{3}{|c|}{ Caris-Verhallen et al. 1999b; Chatwin 2008; Cossette et al. 2006; Daubenmire et al. 1978; Jones 2003; Mallett 1999; Oliver and Redfern1991 } \\
\hline \multicolumn{3}{|c|}{ Non-research literature } \\
\hline \multicolumn{3}{|c|}{$\begin{array}{l}\text { Brown 1997; Carlson 1972; Castledine 2004; Darmann 2002; Davies 1994; Flaskerud 1986; Fry 1994; Gastmans 1998; Harding 1987; Klein 2005; Lein and Wills 2007; } \\
\text { Lomax 1997; Moreira et al. 1997; Nordby 2006, 2007; Sarvimäki 1988; Scheiner and Knipfer 2006; Smith-Stoner 1999; Sumner 2001; van Maanen 2002; Watson 2005; } \\
\text { Williams et al. 2005b }\end{array}$} \\
\hline
\end{tabular}

and to what extent they are used synonymously or are clearly distinguished. It was of interest which communication theories of adjacent sciences were used and what their contribution to nursing science can be or already is.

\section{Definitions of interaction}

Interaction was almost never clearly defined or delineated from communication. In most cases the terms were used interchangeably. In many publications only an implicit differentiation could be found, suggesting a hierarchical relation of communication and interaction, with interaction as the superior concept and term (Harding 1987; Hollinger and Buschmann 1993). Oliver and Redfern (1991) defined interaction as the observable behavior during communication implying a different perspective.

Symbolic interactionism was often used as a theoretical framework to describe the interaction process (Anderson 1979; Carlson 1972; Shattell 2004; Spiers 2002). Alternatively, the closely related model of systemic constructivism was used (Darmann 2002; Flaskerud 1986). Both define interaction as a mutual process of in- 
terpretation and construction of meaning. The achievement of an intersubjective understanding of a situation or an object is a possible result of interaction. Moreover, interaction determines the subjective experience of relationships (Tuckett 2007).

Interaction was mainly characterized by its process-like dynamic structure (Anderson 1979; Larsson and Starrin 1990) and its similarities to the nursing process or the process of nursing action, in this way stating its central meaning for nursing itself (Flaskerud 1986; Gastmans 1998). Interaction is seen as pivotal, especially for psychiatric nursing where the use of self and interaction must also be viewed as a therapeutic means and intervention to improve health outcomes (Cleary and Edwards 1999; Diers et al. 1972; Williams et al. 2005b). Mutuality is mentioned as an additional attribute of interaction (Dornheim 2003; Hansebo and Kihlgren 2002; Rundell 1991; Salyer and Stuart 1985); it starts naturally and happens between two individuals. Dornheim (2003) describes the mutuality of interaction as a process of cognition and action of the participants. These actions can be physical acts, acts of interplay, or a contact or bond of verbal or nonverbal communication (Rundell 1991). Davies (1994) states that it is impossible to interact passively, stressing the behavioral component of interaction. As a whole, interaction is dependent on situational factors and can be identified as the normative claim to right (Sumner 2001). Linguistic interaction as a kind of social interaction always means a situation in which power is exerted through and shown by language (Hewison 1995a).

\section{Definitions of communication}

As communication and interaction are quite often used interchangeably or synonymously, it is not surprising that certain characteristics of both concepts are quite similar. Communication is also seen as a dynamic, complex, and context-related ongoing multivariate process in which the experiences of the participants are shared (Daubenmire et al. 1978; Edberg et al. 1995; Hansebo and Kihlgren 2002; Harding 1987; Sheldon et al. 2006). Mutuality and simultaneity are central aspects in communication (Daubenmire et al. 1978; Davies 1994; Harding 1987; Shattell 2004; Turnock 1991), too.

Table 2 Types of communication researched/types of research results

\begin{tabular}{|c|c|c|}
\hline \multirow[t]{5}{*}{ Descriptive research } & & 46 \\
\hline & Verbal communication & 25 \\
\hline & Nonverbal communication & 13 \\
\hline & Verbal and nonverbal communication & 2 \\
\hline & Relation & 6 \\
\hline Conceptual research & & 20 \\
\hline Intervention research & & 8 \\
\hline
\end{tabular}

Communication is strongly dependent on the culture, the social status, and reciprocal relationships of the participants (Mathews 1983).

The exchange of information with the aim of understanding is the central characteristic of communication (CarisVerhallen et al. 1997; Nordby 2007; Tacke 1999; Usher and Monkley 2001; van Maanen 2002; Vivian and Wilcox 2000). This can only happen in social situations, meaning the existence of a counterpart is a necessity for communication (Sarvimäki 1988). Communication is said to happen always when people meet (Scheiner and Knipfer 2006). The nature of communication in general is described as either affective or instrumental or a mixture of both by some authors (CarisVerhallen et al. 1997, 1998; Lein and Wills 2007). Instrumental communication is also called task-related communication (Caris-Verhallen et al. 1998) or compliance communication (i.e., communication to promote or improve compliance or adherence). Communication as it occurs in nursing assessment and education of patients is instrumental, too (Williams and Gossett 2001). Salyer and Stuart (1985) mention the possibility of a positive or a negative communication related to the affective nature of communication. In the context of nursing, most communication is committed to a certain aim and intention (Diers et al. 1972) mainly to improve the health state of the individual (Flaskerud 1986; Shattell 2004). The actual goal of a communication determines to a great extent the way of communication (Caris-Verhallen et al. 1998).

Communication constitutes an important part of the quality of nursing care and predominantly influences patient and resident satisfaction; it is a core element of nursing care, a fundamentally required nursing skill (CarisVerhallen et al. 1999a; Dean et al. 1982; Gastmans 1998; Hansebo and Kihlgren 2002; Hewison 1995b; Jones 2003; Rundell 1991; Tuckett 2005; Williams and Gossett 2001; Williams et al. 2005a).

Interpersonal or therapeutic relationships are continuous processes of communication; consequently communication can be seen as a prerequisite for relations (Caris-Verhallen et al. 1999b; Moreira et al. 1997; Rundell 1991; Tuckett 2007).

Verbal and nonverbal expressions make up communication (Darmann 2002), with verbal expressions in the form of language being viewed as basic (Lomax 1997). In interactional situations all kinds of behavior are communicative and convey messages (Daubenmire et al. 1978; Davies 1994).

The adaptation of individuals to other persons or objects happens through communication (Daubenmire et al. 1978). This is achieved by communicating and negotiating individual goals and interests (Mathews 1983; Shattell 2004).

The individual gets the opportunity to perceive itself through communication by expressing emotions and memories to others consciously or unconsciously. Communication 
Table 3 Settings/clients researched

\begin{tabular}{|c|c|c|}
\hline \multirow[t]{8}{*}{ Homecare } & & 9 \\
\hline & ominal/vascular/neuro-surgery, gynecology, neurology, internal medicine & 1 \\
\hline & Elderly patients & 2 \\
\hline & Aphasic stroke patients & 1 \\
\hline & Adults & 1 \\
\hline & Nospecial patientgroup & 1 \\
\hline & Home health-care patients, not further described & 2 \\
\hline & Single case, immigrant & 1 \\
\hline \multirow[t]{14}{*}{ Hospital } & & 21 \\
\hline & Adult psychiatric patients & 4 \\
\hline & ominal/vascular/neuro-surgery, gynecology, neurology, internal medicine & 1 \\
\hline & sive care patients, cardiologic patients, thoracic patients, dialysis patients & 1 \\
\hline & Intensive care patients & 2 \\
\hline & sedated or unconscious and without inhibiting neuromuscular medication) & 1 \\
\hline & High dependency unit (thoracic and heart surgery) & 1 \\
\hline & Aphasic stroke patients & 1 \\
\hline & Internal medicine ward as a nursing development unit (acute ill patients) & 1 \\
\hline & Young female's situation on admission in a cancer clinic & 1 \\
\hline & Elderly patients & 2 \\
\hline & Patients with long-term illness & 1 \\
\hline & Counseling situation & 1 \\
\hline & Not further described & 4 \\
\hline \multirow[t]{4}{*}{ Nurse practitioners } & & 4 \\
\hline & No special group of patients & 1 \\
\hline & Young women undergoing an osteoporosis-related education program & 1 \\
\hline & Primary care & 2 \\
\hline Nursing homes & & 21 \\
\hline \multirow[t]{5}{*}{ Homes for the elderly } & Oriented patients and patients with dementia & 1 \\
\hline & Patients with dementia & 1 \\
\hline & 55 years and older & 1 \\
\hline & Including home care patients & 2 \\
\hline & Geriatric patients & 2 \\
\hline \multirow[t]{5}{*}{ Nursinghomes } & Patients with dementia & 3 \\
\hline & Elderly residents & 5 \\
\hline & Nursing home residents, comparison of migrant and native residents & 1 \\
\hline & Psychiatric residents & 1 \\
\hline & Long-term care & 1 \\
\hline Continuing care/rehabilitation ward & Above 65 years & 2 \\
\hline Continuing care ward & Elderly residents & 1 \\
\hline
\end{tabular}

is even seen as a prerequisite of consciousness of the self itself (Hansebo and Kihlgren 2002; Moreira et al. 1997).

Important elements of communication are sender, recipient, message, and context (Hollinger and Buschmann 1993). People transmit and receive signals that they encode and decode in order to understand what is communicated (Davies 1994). A successful communication furthermore demands an accordable cognitive effort and awareness of the participants of the communication (Larsson and Starrin 1990).

Communication is often divided in verbal and nonverbal communication. Nonverbal communication involves all communicative behavior except the spoken word (Caris-
Verhallen et al. 1999b). All behavior can convey messages and meaning, suggesting that all patient behavior has a communicative meaning and message, too (Aguilera 1967). These messages can be transmitted by vocal nonverbal and nonvocal nonverbal means (Oliver and Redfern 1991). Van Maanen (2002) reduces nonverbal communication to mere body language and furthermore categorizes verbal communication as objective communication and nonverbal communication as a form of subjective communication. The importance of nonverbal communication can be stressed by the statement that nonverbal communication has to be used and understood consciously by nurses to fully achieve the goals of communication (Aguilera 1967). 


\section{Relation of interaction and communication}

As mentioned above, the relation of interaction and communication is not clearly defined in nursing literature. The terms are often used interchangeably, and a clear theoretical definition is avoided or rather implicit. The articles that try to clarify the relation of both concepts see communication as a special or subtype of interaction (Dean et al. 1982; Hansebo and Kihlgren 2002; Harding 1987; Hollinger and Buschmann 1993; Sarvimäki 1988; Sumner 2001). Usher and Monkley (2001) describe communication as a promoter of interaction, suggesting that communication is the tool for interaction. Darmann (2000) reports a frequent interchangeable use, too, but states that a difference of both can seldom be found in the reality of communication or interaction. Consequently, the differentiation of these concepts seems a rather theoretical issue, and one cannot be described or defined and understood without the other.

\section{Nurse-patient relationship and communication}

Theoretical reflections on the nurse-patient relationship The nurse-patient relationship is primarily mediated by verbal and nonverbal communication (Aguilera 1967). Like communication, relationships are unique situations (Anderson 1979) and are mutually constructed whereby the professional nurse-patient relationship is responsive and intersubjective (Aranda and Street 1999). It is this interpersonal relationship that makes the difference between nursing and caring (Tuckett 2005). The nursepatient relationship is said to be of importance for patient participation in nursing care (Millard et al. 2006). In the discourse of nurse-patient relationships, there are frequently encountered concepts like empathy, intimacy, and esthetical distance, concepts relevant to communication and interaction, too (Larsson and Starrin 1990). This further reflects how strong the concepts of interaction, communication, and relationship are intertwined.

Empirical findings on nurse-patient relationship Two concepts are identified as important in interaction and relationships, "being authentic" and "being a chameleon," meaning the necessity of two divergent behaviors in interaction and relationship (Aranda and Street 1999). So nurses have to be authentic and adaptive to the patient and the situation. The professional relationship is an important aspect of nursing interventions and can have positive or negative effects on the nursing experience of patients (Breeze and Repper 1998). Anderson (1979) even states that the nurse-patient relationship has the power to create or destroy those who came to us for care as individuals create themselves through relationships. Patients described nurse-patient relationships as good when they had the feeling of having been treated respectfully, essentially as a valued person (Breeze and Repper 1998). Nurses in nursing homes often take over roles of significant others for the residents (Carlson 1972). Seen by Peplau as the essential aspect of nursing, relationships are dependent on the skills of the nurse like nonjudgmental listening and the ability to convey warmth and understanding (Castledine 2004; Gastmans 1998).

The importance of the nurses' listening behavior was shown by Gilbert (1998), who identified six relational message factors that were communicated by nurses' listening behavior: trust/receptivity, depth/similarity/affection, difference, dominance or power, formality and composure. The listening behavior in the way of listening and asking actually is the beginning of the nurse-patient communication relationship (Carlson 1972). Furthermore, it appears that positive nurse-patient relationships can be communicated in a short period of time (Gilbert 1998).

Mutuality, too, is a central aspect of relationships and refers to the validation of people in a relationship, meaning the sharing and acknowledging of differences, it is also influenced by the interaction of people's views of the purpose of the meeting (Hansebo and Kihlgren 2002). In the promotion of a mutual sense of togetherness with the patient seven influencing factors of interaction and communication were identified: promoting competence, struggling for cooperation, deep communication for communion, showing respect for the unique person, skills in balancing power, distance in a negative point of view, and fragmentary nursing situations (Hansebo and Kihlgren 2002).

The therapeutic relationship is constructed in a set of cultural values that often reflect the majority culture: rugged individualism, autonomy, competition, progress and future orientation, the scientific method of inquiry, the nuclear family structure, assertiveness, and rigid timetables (Canales 1997). Different perceptions held by nurses and patients can be identified as a major obstacle to nursepatient relationships (Cleary and Edwards 1999). The nature of the staff-patient relationship still is different from that between relatives and patients as by definition it is a therapeutic one (Moore and Kuipers 1992; Moreira et al. 1997). As transference and counter-transference occur in the context of relationships, these dynamically interrelated and intrapsychically occurring processes have to be taken into account by the nurse in the layout of the therapeutic relationship (O’Kelly 1998).

While nurses are often not sure about the effect of the nurse-patient relationship, patients appreciate to a high degree the relationship as a therapeutic one whereby the relationship occurs even in temporally short interactions when certain circumstances apply (Shattell 2004). Altschul (1972) as described by Schröck (2003) holds the view that nurse-patient relations only occur if communication does not happen in routine interactions. The patient's perception 
of the quality of the communicative relationship with a health-care provider is associated with both patient satisfaction and compliance, in this way influencing the process of care and eventually its outcome (Vivian and Wilcox 2000).

In psychiatric nursing relationships take a central role, as it is assumed that a patient who experiences a relationship to a helper as intimate and secure is probably more apt to communicate his or her inner feelings and experiences to the helper, which is often seen as a prerequisite for psychiatric care and treatment (Larsson and Starrin 1990). Irrespective of the field of nursing, Spiers (2002) demands that nurses must be skilled in developing effective relationships with their patients.

\section{Used theories of communication}

Communication models and concepts that were used or mentioned in the articles can be seen in Table 4. The by far most referred to models were symbolic interactionism and classic sender-receiver models. As the used theories were not further described in the articles, it is unclear whether the theories are normatively or empirically based.

Compared to the use of theories of adjacent sciences, the use of original nursing theories related to communication is rather infrequent (see Table 4). All found nursing theories were Grand Theories.

The most frequently used nursing theories were Peplau's theory of interpersonal relations (Caris-Verhallen et al. 1997; Castledine 2004; Gastmans 1998) and King's interacting systems framework (Caris-Verhallen et al. 1997, 1998; Rundell 1991).

Empirical findings and normative statements on characteristics of interaction and communication

\section{Structures of communication}

Empirical findings on the structures of nurse-patient communication of included articles will be presented in this section. Mere theoretical reflections will be accented accordingly.

The role allocation in nurse-patient communication and interaction seems to be quite clear. Patients take on the role that is expected of them, namely the role of being sick, dependent, and inactive (Armstrong-Esther and Browne 1986). This kind of role allocation is typically associated with the different power assigned to the roles 'nurse' and 'patient' (Diers et al. 1972). These roles are expressed in the kind of interaction that happens (Mathews 1983), for example, the use of touch as a method of communication (McCann and McKenna 1993), but can vary in different settings, for example, home care and hospital (Shattell
2004). These empirical findings support the theoretically derived statements of the supreme importance of role behavior and role expectations in communication (Scheiner and Knipfer 2006).

Different registers used by patients and nurses are structural aspects of communication that add to asymmetrical power allocation as the nurse is able to use the patient's register, but has also the opportunity to use the medical register, in this way disabling the adequate participation of the patient in the communication (Bourhis et al. 1989). In his conceptual essay, Nordby (2006) describes this situation as a result of different backgrounds of nurses and patients. Nordby recommends that the nurse should rather correct misunderstandings than adopt the patient's idiosyncratic conception. In this way, the nurse tries to avoid that the patient feels alienated from the medical register. Language in terms of registers was shown to be a tool of power that indicates the relative power of the communicators (Hewison 1995a, b). The use of a wide range of conversational tactics to maintain control over verbal nurse-patient interaction by nurses confirms this, too (May 1990). An often not consciously used mode of speech conveys relative power in conversations, the so-called elder speak. This speech modification covers the use of diminutives, inappropriate plural pronouns, tag questions, shortened sentences, slow speech rate, and simple vocabulary (Williams et al. 2005a, b). Jones and van Amelsvoort Jones (1986) observed that verbal communication in a nursing home largely occurred in the form of commands, which can be interpreted as a form of overt power.

In a nursing home for demented patients, Edberg et al. (1995) observed five types of communication content/ orientation: orientation to person, orientation to task, orientation to task and person simultaneously, split or nonsense communication, and inattentive communication, whereas nurses mostly used task-oriented communication, and patients' communication was mainly split or personoriented. A similar tendency was shown in psychogeriatric units. There was little staff-patient communication as with confused patients communication was cut short mostly and staff-patient interaction took the form of statements or instructions (Armstrong-Esther and Browne 1986). Sometimes patients with dementia and vocally disruptive behavior are even addressed as an object (Graneheim et al. 2001). This parental custodial communication style of nurses can be found in psychiatry, too (Cleary and Edwards 1999). Hansebo and Kihlgren (2002) identified the nurses as nearly solely responsible for the quality of the communication between themselves and demented nursing home residents. In their sample they observed the carers rather balancing in their interactions, verbal as well as nonverbal, to promote a sense of mutual togetherness with the residents (Hansebo and Kihlgren 2002). In nursing homes, 
Table 4 Used theories of communication, interaction, and relationships

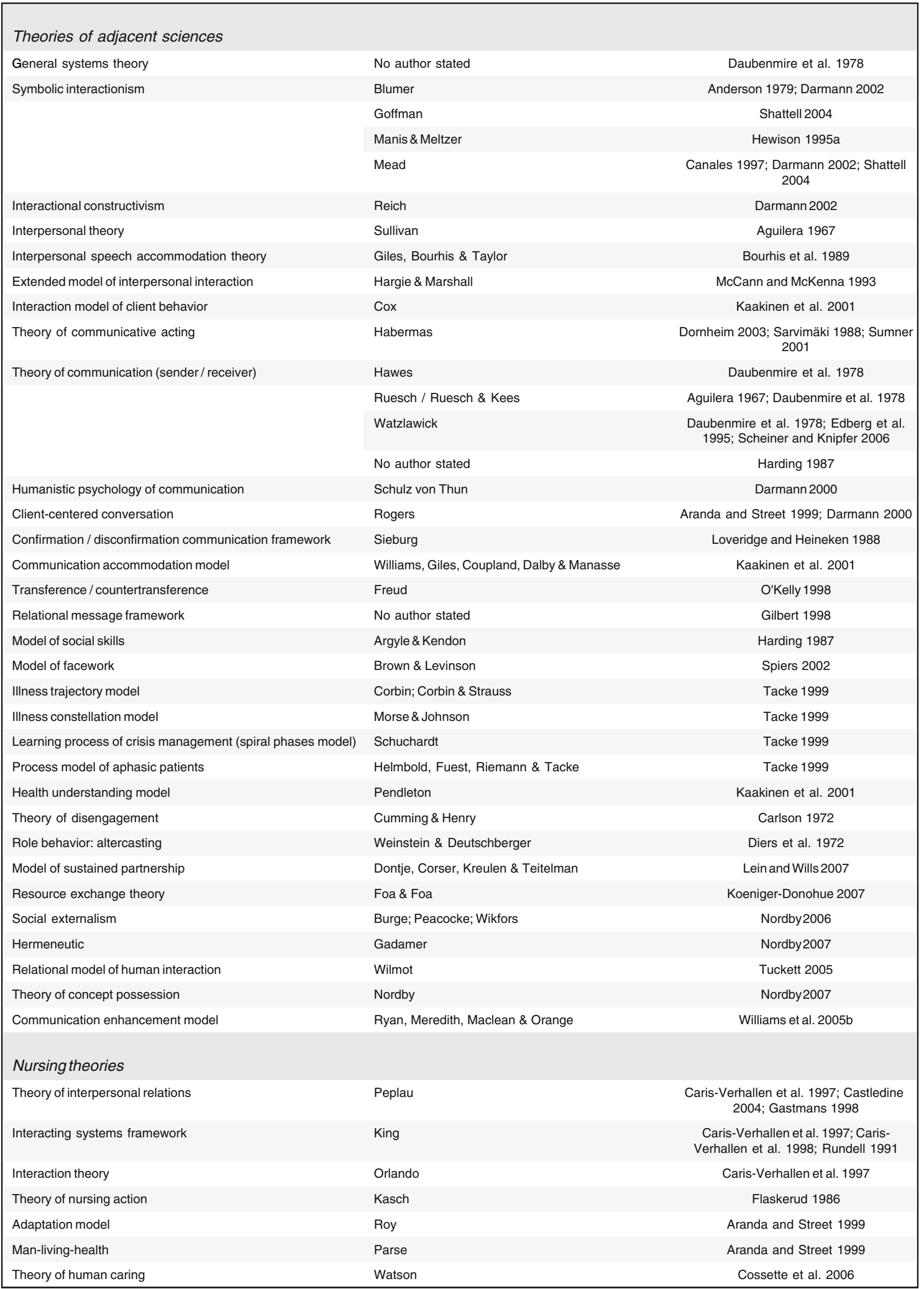


the biggest part of residents' communication opportunities is provided by the nursing home staff (Williams et al. 2005a). Further, investigation of this communication revealed about $69 \%$ of the conversations were rather nursing task-oriented, and only few conversations took longer than 5 min (Williams et al. 2005a).

In a different setting nurse practitioners seem to employ other communication strategies and categories. Seven categories show what nurse practitioners place emphasis on in communication with elderly patients: client involvement, client health beliefs, compliance gaining tactics, client education, client support systems, competent communicator skills, and hypervigilance to the client (Kaakinen et al. 2001). This corresponds with the theoretical reflections of Lein and Wills (2007).

Darmann identified central structures in the nurse-patient communication: power of the nurses, decisional freedom of the patients and nurses, and measures of the patient to exert pressure (Darmann 2000). Power and control also seem to be the main issue with so-called 'difficult' patients in psychiatric care. Despite the different roles and overt power imbalance between nurses and patients, these patients appeared to be struggling for control, battling for power with the nurses (Breeze and Repper 1998). Patients are labeled as 'difficult' when they challenge or threaten the nurses' competence or control (Breeze and Repper 1998). Kettunen et al. (2002) also see autonomy and power as central structures of nurse-patient communication. The way in which power and control are exerted in communication is described in another study as confirmation or disconfirmation behavior (Loveridge and Heineken 1988). Information policy of the institution is another power-related structure in communication as not all staff may be allowed to share all information with the patient or resident (Tuckett 2007). This situation can lead to communication strategies of avoidance and evasion (Tuckett 2007).

Vivian and Wilcox (2000) depict the structure of compliance communication in home care nursing as embedded in a continuous conversation in which nurse, patient, and relatives are involved. The dimensions of compliance communication are an affiliative dimension with the intention to create a personal bond or link and a control dimension with the intention to control compliance and adherence (Vivian and Wilcox 2000).

\section{Process of communication}

This paragraph will show how the process of communication and interaction is constructed and which factors have direct or indirect influence on the process of communication/interaction according to the research results of the included articles.

The process of communication is often described with a phase model, e.g., initiating phase, working phase, and terminating phase (Edberg et al. 1995) or perception, presencing, and reassurance (Usher and Monkley 2001). These models for single communications are supplemented with phases on a more abstract level like the progression of the admission, so Rundell (1991) identified phases of changing interactive privileges for patients during admission on a high dependency unit. Turnock (1991) observed a negative correlation of communicative behavior and the health status on the ICU meaning a lack of communication in a phase when the patient would be able and in need of communicative interaction. Another process model is the one used by Sumner (2001) and comprises the development of moral maturity that directly influences communication. Van Maanen (2002) describes communication as a dynamic and continuous process, similar to the nursing process.

Certain factors that influence the process of communication and interaction were found. The cognitive status of the patient influences the process, so on the one hand demented patients often have an extended latency period and are more often inattentive in a communication (Edberg et al. 1995); on the other hand, the communication style of nurses with these patients shows that the use of verbal communication is reduced, only minimal verbal interactions happen during nursing care, and when it occurs primarily orders are given (Jones and van Amelsvoort Jones 1986). Communication often happens during medical tasks (Berg et al. 2007). The setting determines the communication process, too, as Tacke (1999) could show in a review of qualitative studies for different communication processes of aphasic patients in acute care and rehabilitation wards. Quite often the communication process can be described as inadequate, superficial, and stereotyped (Dean et al. 1982). The number of present nurses had an impact on the quality of the communication, meaning with two or more nurses involved in the interaction process, the attentiveness to the patient was reduced (Edberg et al. 1995).

Mutuality in communication as stated in the normative definitions of communication shows itself in the process of communication in several ways. So feedback is required to sustain the process of interaction (Armstrong-Esther and Browne 1986), and the occurrence of reciprocal action was observed, meaning that a positive action yields a positive reaction and a negative action a rather negative reaction (Salyer and Stuart 1985). Routasalo and Isola (1998) documented in a geriatric nursing home that nurses almost always initiated interaction with a touch and also ended it with a touch. Beneath the behavior of the health-care professionals, the communication behavior of the patients shows a significant impact on the communication process, too, so behaviors like questioning, disclosure of health knowledge and experience, and interrupting the nurse are appropriate to influence communication (Kettunen et al. 2002). 
Different registers (medical language and everyday language) of patients and health-care professionals influence the process of communication. Bourhis et al. (1989) describe three possible courses of the process in his conceptual paper when different registers are involved: convergence, maintenance, or divergence. To influence the process of communication, nurses sometimes use tactics to control or even avoid communication (May 1990).

\section{Intentions of communication and interaction}

Intentions and issues of communication and interaction in patient care that can be often found in nursing literature are described in this paragraph. The normative character of intentions and aims is reflected in the literature. In this way we found many articles with rather normative than empirically based statements. Therefore, we will first describe the normative theoretical statements and will close with the empirical results of the included articles.

The main intention of communication and interaction in the health setting should be to influence the patient's health status or state of well-being (Flaskerud 1986; Gastmans 1998). Sarvimäki (1988) proposes to achieve this by orienting interaction and communication toward understanding the patient. Communication or narrative interaction thus enhances nurses' understanding of the patient (Canales 1997).

Turnock (1991) defines 'good' communication in the ICU: providing information about their surroundings, telling about the health status and progress, warning about procedures, introducing staff, and explaining sounds in the ICU. The intention of this kind of communication is called 'orienting patients to their environment' (Turnock 1991). Another intention of communication in the health setting can be problem solving, representing another instrumental intention of communication (Moreira et al. 1997). Silence as a means of nonverbal communication can be used to promote acceptance, concern, and support for the patient (Lomax 1997).

Mostly interpersonal contexts are communicated: negotiating territoriality, sharing perceptions, establishing an amicable working relationship, synchronizing role expectations, and negotiating knowledge to achieve these goals (Spiers 2002).

Privacy, identity, autonomy, and security were identified as central issues of communication with demented patients in nursing homes, but quite often communication is taskoriented in this setting (Graneheim et al. 2001).

The view of communication as a kind of therapeutic tool strongly depends on the definition of communication as work or non-work by nurses as May discovered (1990). Conscious use of nonverbal communication techniques, especially the use of touch, are intended to convey comfort, caring, and reassurance (Hollinger and Buschmann 1993), in this way improving the well-being of the patient or resident. To reach the patient on a personal and emotional level, skillful helpers use communication of everyday character (Larsson and Starrin 1990). In the investigation of Martin and Barkan (1989), it was shown that communication and interaction aimed at facilitating the understanding of the patients improved the well-being of the patients.

\section{Reported perceptions of important quality aspects} in communication and interaction in the nursing setting

The quality of communication in the nursing setting depends on several factors as studies show. From the patient's view the following behavior of nurses is accountable for a rather negative communication experience with nurses: stereotyping, custodialism, rule enforcement, lack of intimacy, and lack of friendliness, empathy, and caring (Cleary and Edwards 1999). From the nurses' view, the quality of communication is influenced by the attention a nurse pays to the details of sending a message (Usher and Monkley 2001). A shared perspective of patients and nurses is the claim to truth and claim to truthfulness in communication (Sumner 2001).

\section{Nonverbal behavior in relation to communication}

In this paragraph nonverbal behavior and the way it is included in communication in the sample will be described.

First of all, the kind of behavior that constitutes nonverbal communication will be defined; it includes physical contact/touch, proximity/personal space, physical orientation, body posture, head nods, facial movements, gestures, looking/eye contact, and paralinguistic aspects of speech (Harding 1987; Davies 1994).

Touch is the most frequently researched mode of nonverbal communication in our nurse-specific sample. Generally, two forms of touch were identified and distinguished, 'expressive touch' and 'instrumental touch' (McCann and McKenna 1993; Oliver and Redfern 1991). 'Expressive touch' in communication is often used to communicate comfort, empathy, caring, and reassurance, whereas 'instrumental touch' means necessary touch during or for certain nursing interventions, e.g., body care (Hollinger and Buschmann 1993). McCann and McKenna (1993) discovered 'instrumental touch' as the dominating form of touch in a continuing care/rehabilitation setting (95.3\%). One can conclude that touch is rather seldom used as a conscious means of communication.

Touch as a means of communication thereby is perceived according to the 'touch' context, taking into account cultural perception of touch, role of the persons that are 
interacting by touch, touch socialization, age, gender, part of the body touched, and the qualitative nature of touch (Aguilera 1967; Hollinger and Buschmann 1993; McCann and McKenna 1993; Oliver and Redfern 1991; Routasalo 1999; Routasalo and Isola 1998). Conscious or cognizant use was found to be effective in establishing and maintaining simple verbal communication and therapeutic communication (Aguilera 1967; Routasalo and Isola 1998). Touch gestures were found to improve the quality of verbal communication (Aguilera 1967).

Silence as a form of paralanguage can have several meanings like a sign of power, trust, acceptance, or simply a sign that a person has finished what it is saying and is waiting for a response (Lomax 1997; Loveridge and Heineken 1988). Other forms of nonverbal communication that were investigated were nonverbal aspects of speech like paralanguage, body language, and so on (Fry 1994).

In general, nonverbal communication was described as an opportunity to start and sustain verbal communication (Davies 1994; Fry 1994; Harding 1987). According to the statements in the sample, nonverbal communication seems to play a rather supportive role to verbal communication.

\section{Predictors and influencing factors}

Generally, influencing factors can be theoretically organized into the categories of provider variables, patient variables, and environmental and situational variables (Caris-Verhallen et al. 1997; Park and Song 2005; Routasalo and Isola 1998; Ruan and Lambert 2008). A more detailed illustration of these categories will be provided in the following paragraph. It is still difficult to delineate separate factors or variables for a complex subject like communication or interaction as the factors are largely interconnected. In order to avoid redundant listing of variables, we will list identical provider and patient variables under "shared variables."

Provider variables The most often mentioned provider variable is the communication skill of the nurse. Communication skill includes an extensive repertoire of communication strategies, interpersonal competence (Fosbinder 1994), the ability to personalize the approach to the clients, meaning rate of speech, connecting to the clients' life world, tone of voice, and using shared language (Kaakinen et al. 2001). Other concepts subsumed under communication skill were trust, knowledge, caring, respect, and courtesy (Breeze and Repper 1998). Guidelines for better communication often emphasize trust and empathy as crucial to effective communication (Heineken 1998; Moreira et al. 1997). Nurses should investigate client and family sick role beliefs so they can interact adequately with the clients and their families (Heineken 1998).
The nurses' self-awareness of their communication methods was stressed as important, too (Martin and Barkan 1989). Additional proposed provider variables are the nurses' educational level, showing that nurses of lower educational level do more social communication than nurses of higher educational level, the experience of the nurse regarding affective communication, the nurses' attitude toward patients, and their intrinsic job motivation (Caris-Verhallen et al. 1999a; Tuckett 2007).

Interventions can improve the communication skill of patients, too, as, for example, Tacke (1999) has shown with aphasic patients. Nurses' educational level influences the pre-understanding or prior knowledge of the nurses, in this way influencing communication as well (Darmann 2002). So it can be concluded that nurse education is a central determinant for an effective communication. In a study in a psychiatric setting, patient interviews revealed influencing factors from patients' view like nurses' attributes, role perceptions, clinical care, and time (Cleary and Edwards 1999). Dean et al. (1982: 255) described communicative competencies of nurses as the "ability to ask appropriate questions, listen, explore a topic, maintain a conversation, and recognize and respond to cues from patients".

Patient variables Patients speaking only foreign languages often have little information about their illness and treatment, resulting in bad communication and possibly worse outcomes (Goode 2004). Mathews (1983) in his review found interrelation factors like social distance or patients' perception that nurses do not have authority to communicate information to them. Communication difficulties with aged patients are mainly determined by physiologic changes like prolonged time to perceive, to respond, to learn, to move, and to act (Carlson 1972). Carlson (1972: 278) describes intrapersonal competence as "before one can communicate in the fullest sense, one must also be able to listen in the fullest sense." With demented patients the responsibility for successful communication is for the most part with the nurses (Hansebo and Kihlgren 2002). The kind of disease, especially regarding dementia, is crucial to the course of communication (Edberg et al. 1995). Visual disabilities of the patients have a high impact on the perception of paralanguage, in this way affecting the process of communication as important cues cannot be recognized (Fry 1994).

Shared variables Successful and smooth interaction was characterized by Spiers (2002) by the ability of both nurse and patient to synchronize their responses to match each perceived and expressed sense of self-image in three primary areas of public social image, namely autonomy, competence or esteem, and solidarity.

Touching or the nurse's touching style as a special kind of communication is determined by several factors, such as 
the cultural background, nursing school, general working style in patient interactions, and the feedback from the patients (Routasalo 1999). Theses factors can be categorized in nurse variables, patient variables, and daily contextual variables similar to the above-mentioned tripartite categorization (Routasalo 1999). McCann and McKenna (1993) state the perception of touch is mainly influenced by personal factors, meaning nurse and patient variables. They mention factors like age, gender, health status, social status, previous tactile experience, touch socialization, and the role taken (McCann and McKenna 1993). Aguilera (1967) describes necessary preconditions that have to be met for the use of touch as a conscious means of communication: it must be acceptable for both nurse and patient, and it must be recognized that touch has a unique meaning to each person. Non-verbal aspects of communication are learned in different cultural settings and are mostly learned intuitively by the individual (Lomax 1997). Perception and importance of possible communication barriers is to a high degree dependent on the cultural background of patients and nurses as the studies of Park and Song (2005) and its replication by Ruan and Lambert (2008) have shown.

A minimal mutual compatibility of the communicators' realities like language has to be existent to achieve a successful exchange of information between nurse and patient. The patients' means to successfully negotiate their interests in the clinical setting are limited due to the specialized field of medical knowledge, and they strongly depend on the health professionals. The use of jargon or a special register by the nurses affects the path of nursepatient communication and patient participation in the clinical setting (van Maanen 2002; Williams et al. 2005a). The use of medical and everyday language in the hospital setting is determined by the linguistic background of the patient and nurse, motivational factors, communicative norms in the hospital setting, and status and power differentials in the hospital setting (Bourhis et al. 1989). The nurse-related behavior of patients influences the way nurses interact with them, stressing the mutuality aspect of communication, too (May 1990).

A very important barrier for communication is the labeling and stigmatization of certain patient groups or minorities (Canales 1997). Power differentials in the nursepatient relation determine the course of communication (Darmann 2000; Shattell 2004).

Environmental variables Different settings show different communicative behavior by nurses as was shown for home care compared to nursing homes (Caris-Verhallen et al. 1998). The amount of interaction in homes for the elderly depended on the resident's mental status, meaning nurses interacted less with demented residents (Armstrong-Esther and Browne 1986). Psychiatric nurses identified influencing factors from their perspective as environmental factors like available rooms and ambience of the ward, something unplanned that always comes up and interferes with communication, instrumental support and the focus of nursing in the hospital (Cleary and Edwards 1999; Cleary et al. 1999). It was concluded that mainly occupational stress, organizational structure, occupational culture, and bureaucratic constraints influence nurse-patient communication in the psychiatric setting (Cleary and Edwards 1999). Staffing, pressure of organizational set-up, and given role demands have to be seen as situational and environmental factors that contribute to communication (Dean et al. 1982; Larsson and Starrin 1990; Mathews 1983). Darmann (2002) stated that the environmental factors result in different levels of decisional freedom.

Regarding predictors and influencing factors, it can be concluded that there is no one single quality or aspect of communication that stands alone as the key to establishing effective communication (Usher and Monkley 2001).

\section{Conclusion}

This review described the professional communication in the field of nursing and caring. Two aspects seem to be important: first, using of definitions of the basic concepts and theoretical backgrounds to classify findings into underlying theoretical comprehension, and second, description of structural aspects and the process of communication by empirically based findings about the nurse-patient communication and interaction.

It is rather surprising that in nursing literature the proprietary nursing theories including interaction and communication are hardly used. Nursing scientists have preferred theories of other sciences like sociology and psychology. Watson (2005) also criticizes this aspect exemplarily in a commentary on the review of Shattell (2004) and demands to integrate contemporary nursing care theories in order to reach beyond interaction to authentic caring relationships. She defines this as a goal for nursing science as she thinks that foreign theories cannot reflect the unique situation of the nurse-caring relationship (Watson 2005). In this way, nursing science has to develop its own perspectives and theories, and should not merely adopt perspectives of other disciplines. Therefore, some issues have to be clarified by nursing theorists: the necessity of a nursing-care-based communication theory and the appropriateness of communication theories of adjacent sciences according to certain settings or demands. There is sufficient general descriptive and conceptual research for nursepatient interaction and communication. Communication 
and interaction skills are almost always seen as crucial for nurses. The authors of the included citations all conclude that these skills can be learned to a certain degree. Often the term "communication skill" was not clearly defined and was rather nebulous. Without clarification of concepts, findings from publications are exposed to the risk of misinterpretation.

Rather surprising was the vast amount of research quantitatively evaluating data generated with classically qualitative methods. Mostly lacking are well-designed randomized controlled intervention studies with appropriate outcomes that would underpin the effect of educational or structural interventions to improve communication. Intervention studies seldom described the investigated intervention program. Chosen outcomes for the evaluation were not clinically relevant, such as duration or frequency of interactions. Further, patient involvement and their role in communication are often neglected by authors. Considering the mutual nature of communication, the patients' share in conversation should be taken more into account than it has been until now. Bearing in mind the mutuality of communication and interaction, the responsibility for a working communication cannot solely be with the nurses. It has to be specified what contents should be communicated and especially what contents the patient wants to have communicated by the nurse.

Additionally, intervention studies did not make up a large part of our pool. By far the majority were descriptive and conceptual studies. If communication can be practiced and as there are certain deficits in nurse-patient communication, as was shown for demented nursing home residents, implications for nursing practice exist particularly for educational interventions, though their effectiveness lacks evidence. These interventions can be aimed at provider variables, but have to take into account known and problematic patient variables, too. By which means other factors like environmental variables or situational variables can be successfully influenced cannot be stated based on this review. It also cannot be concluded whether nursepatient communication as an important factor for patient satisfaction influences economic outcomes for health institutions.

These are important implications for future theoretical and empirical research in this field, and in this way for the professional focus in nursing, too.

Acknowledgements This project was supported by the German Research Foundation (Ref.: BE 1153/2-1).

Conflict of interest The authors disclose any relevant associations that might pose a conflict of interest.

\section{References}

Aguilera DC (1967) Relationship between physical contact and verbal interaction between nurses and patients. J Psychiatr Nurs Ment Health Serv 5:5-21

Allen CI, Turner PS (1991) The effect of an intervention programme on interactions on a continuing care ward for older people. J Adv Nurs 16:1172-1177

Altschul A (1972) Patient-nurse interaction: A study of interaction patterns in acute psychiatric wards. Churchill Livingstone, Edinburgh

Anderson ND (1979) Human interaction for nurses. Superv Nurse 10 (44):48-50

Aranda SK, Street AF (1999) Being authentic and being a chameleon: nurse-patient interaction revisited. Nurs Inq 6:75-82

Armstrong-Esther CA, Browne KD (1986) The influence of elderly patients' mental impairment on nurse-patient interaction. J Adv Nurs 11:379-387

Barrere CC (2007) Discourse analysis of nurse-patient communication in a hospital setting: implications for staff development. J Nurses Staff 23:114-122 quiz 123-124

Berg L, Skott C, Danielson E (2007) Caring relationship in a context: fieldwork in a medical ward. Int J Nurs Pract 13:100-106

Bourhis RY, Roth S, MacQueen G (1989) Communication in the hospital setting: a survey of medical and everyday language use amongst patients, nurses and doctors. Soc Sci Med 28:339-346

Breeze JA, Repper J (1998) Struggling for control: the care experiences of, difficult' patients in mental health services. J Adv Nurs 28:1301-1311

Brown JM (1997) Manipulativeness and dialogue. J Psychiatr Ment Health Nurs 4:137-144

Burgio LD, Allen-Burge R, Roth DL, Bourgeois MS, Dijkstra K, Gerstle J, Jackson E, Bankester L (2001) Come talk with me: improving communication between nursing assistants and nursing home residents during care routines. Gerontologist 41:449460

Canales M (1997) Narrative interaction: creating a space for therapeutic communication. Issues Ment Health Nurs 18:477494

Caris-Verhallen WM, Kerkstra A, Bensing JM (1997) The role of communication in nursing care for elderly people: a review of the literature. J Adv Nurs 25:915-933

Caris-Verhallen WM, Kerkstra A, van der Heijden PG, Bensing JM (1998) Nurse-elderly patient communication in home care and institutional care: an explorative study. Int J Nurs Stud 35:95-108

Caris-Verhallen WM, de Gruijter IM, Kerkstra A, Bensing JM (1999a) Factors related to nurse communication with elderly people. J Adv Nurs 30:1106-1117

Caris-Verhallen WM, Kerkstra A, Bensing JM (1999b) Non-verbal behaviour in nurse-elderly patient communication. J Adv Nurs 29:808-818

Carlson S (1972) Communication and social interaction in the aged. Nurs Clin North Am 7:269-279

Castledine G (2004) The importance of the nurse-patient relationship. Br J Nurs 13:231

Chatwin J (2008) Hidden dimensions: the analysis of interaction in nurse-patient encounters. Qual Prim Care 16:109-115

Cleary M, Edwards C (1999) 'Something always comes up': nursepatient interaction in an acute psychiatric setting. J Psychiatr Ment Health Nurs 6:469-477

Cleary M, Edwards C, Meehan T (1999) Factors influencing nursepatient interaction in the acute psychiatric setting: an exploratory investigation. Aust N Z J Ment Health Nurs 8:109-116

Cossette S, Cote JK, Pepin J, Ricard N, D'Aoust L (2006) A dimensional structure of nurse-patient interactions from a caring 
perspective: refinement of the Caring Nurse-Patient Interaction Scale (CNPI-Short Scale). J Adv Nurs 55:198-214

Darmann I (2000) Anforderungen der Berufswirklichkeit an die kommunikative Kompetenz von Pflegekräften. Pflege 13:219-225

Darmann I (2002) Bewegung als Interaktion - Systemisch-konstruktivistische Sichtweise von Bewegung und Konsequenzen für die Pflege. Pflege 15:181-186

Daubenmire MJ, Searles SS, Ashton CA (1978) A methodologic framework to study nurse-patient communication. Nurs Res 27:303-310

Davies P (1994) Non-verbal communication with patients. Br J Nurs 3:220-223

Dean M, Misra P, Kakkar DN, Kaur J (1982) Hospital interactions: communication by nursing personnel. Nurs J India 73:254-258

Diers D, Schmidt RL, McBride MA, Davis BL (1972) The effect of nursing interaction on patients in pain. Nurs Res 21:419-428

Dornheim J (2003) Verbesserung der kommunikativen Kompetenz von Pflegenden und Gepflegten. Projektbericht. http://www. bosch-stiftung.de

Edberg AK, Nordmark Sandgren A, Hallberg IR (1995) Initiating and terminating verbal interaction between nurses and severely demented patients regarded as vocally disruptive. J Psychiatr Ment Health Nurs 2:159-167

Flaskerud JH (1986) On 'toward a theory of nursing action: skills and competency in nurse-patient interaction'. Nurs Res 35:250-252

Fosbinder D (1994) Patient perceptions of nursing care: an emerging theory of interpersonal competence. J Adv Nurs 20:1085-1093

Fry A (1994) Effective communication with people with visual disabilities. Nurs Times 90:42-43

Gastmans C (1998) Interpersonal relations in nursing: a philosophicalethical analysis of the work of Hildegard E. Peplau. J Adv Nurs 28:1312-1319

Gilbert DA (1998) Relational message themes in nurses' listening behavior during brief patient-nurse interactions. Sch Inq Nurs Pract 12:5-21

Goode ML (2004) Communication barriers when managing a patient with a wound. Br J Nurs 13:49-52

Graneheim UH, Norberg A, Jansson L (2001) Interaction relating to privacy, identity, autonomy and security. An observational study focusing on a woman with dementia and 'behavioural disturbances', and on her care providers. J Adv Nurs 36:256-265

Hansebo G, Kihlgren M (2002) Carers' interactions with patients suffering from severe dementia: a difficult balance to facilitate mutual togetherness. J Clin Nurs 11:225-236

Harding KP (1987) Implications of social interaction. Nursing (Lond) 3:suppl 4-6

Heineken J (1998) Patient silence is not necessarily client satisfaction: communication problems in home care nursing. Home Healthc Nurse 16:115-120

Hewison A (1995a) Nurses' power in interactions with patients. J Adv Nurs 21:75-82

Hewison A (1995b) Power of language in a ward for the care of older people. Nurs Times 91:32-33

Hollinger LM, Buschmann MB (1993) Factors influencing the perception of touch by elderly nursing home residents and their health caregivers. Int J Nurs Stud 30:445-461

Jones A (2003) Nurses talking to patients: exploring conversation analysis as a means of researching nurse-patient communication. Int J Nurs Stud 40:609-618

Jones DC, van Amelsvoort Jones GM (1986) Communication patterns between nursing staff and the ethnic elderly in a long-term care facility. J Adv Nurs 11:265-272

Kaakinen J, Shapiro E, Gayle BM (2001) Strategies for working with elderly clients: a qualitative analysis of elderly client/nurse practitioner communication. J Am Acad Nurse Pract 13:325-329
Kettunen T, Poskiparta M, Gerlander M (2002) Nurse-patient power relationship: preliminary evidence of patients' power messages. Patient Educ Couns 47:101-113

Klein ER (2005) Effective communication with patients. Pa Nurse 60:14-15

Koeniger-Donohue R (2007) Nurse practitioner-client interaction as resource exchange: the nurse's view (NP-client interaction). J Clin Nurs 16:1050-1060

Larsson G, Starrin B (1990) Patient-nurse interactions: relationships between person characteristics, empathy, content of communication, and patients' emotional reactions. Scand J Caring Sci 4:129-135

Lein C, Wills CE (2007) Using patient-centered interviewing skills to manage complex patient encounters in primary care. J Am Acad Nurse Pract 19:215-220

Lomax B (1997) Learning to understand a patient's silence. Nurs Times 93:48-49

Loveridge CE, Heineken J (1988) Confirming interactions. J Gerontol Nurs 14:27-30

Luhmann N (1993) Das Recht der Gesellschaft. Suhrkamp, Frankfurt am Main

Mallett J (1999) Difficulties of filming interactions. Nurs Times 95:49

Martin LL, Barkan H (1989) Clinical communication strategies of nurse practitioners with patients. J Am Acad Nurse Pract 1:77-83

Mathews JJ (1983) The communication process in clinical settings. Soc Sci Med 17:1371-1378

May C (1990) Research on nurse-patient relationships: problems of theory, problems of practice. J Adv Nurs 15:307-315

McCann K, McKenna HP (1993) An examination of touch between nurses and elderly patients in a continuing care setting in Northern Ireland. J Adv Nurs 18:838-846

McCutcheon HH, Pincombe $J$ (2001) Intuition: an important tool in the practice of nursing. J Adv Nurs 35:342-348

Millard L, Hallett C, Luker K (2006) Nurse-patient interaction and decision-making in care: patient involvement in community nursing. J Adv Nurs 55:142-150

Moore E, Kuipers L (1992) Behavioural correlates of expressed emotion in staff-patient interactions. Soc Psychiatry Psychiatr Epidemiol 27:298-303

Moreira AS, Rodrigues AR, Coler MS (1997) A model for analysis of the nurse-patient interactive process (MAIP). J Psychiatr Ment Health Nurs 4:303-306

Nordby H (2006) Nurse-patient communication: language mastery and concept possession. Nurs Inq 13:64-72

Nordby H (2007) Meaning and normativity in nurse-patient interaction. Nurs Philos 8:16-27

O'Kelly G (1998) Countertransference in the nurse-patient relationship: a review of the literature. J Adv Nurs 28:391-397

Oliver S, Redfern SJ (1991) Interpersonal communication between nurses and elderly patients: refinement of an observation schedule. J Adv Nurs 16:30-38

Park E, Song M (2005) Communication barriers perceived by older patients and nurses. Int J Nurs Stud 42:159-166

Parsons T (1968) Einige theoretische Betrachtungen zum Bereich der Medizinsoziologie. In: Parsons T (ed) Sozialstruktur und Persönlichkeit. Klotz, Frankfurt am Main, pp 408-449

Routasalo P (1999) Physical touch in nursing studies: a literature review. J Adv Nurs 30:843-850

Routasalo P, Isola A (1998) Touching by skilled nurses in elderly nursing care. Scand J Caring Sci 12:170-178

Ruan J, Lambert VA (2008) Differences in perceived communication barriers among nurses and elderly patients in China. Nurs Health Sci 10:110-116

Ruesch J, Bateson G (1995) Kommunikation: Die soziale Matrix der Psychiatrie. Carl Auer, Heidelberg 
Rundell S (1991) A study of nurse-patient interaction in a high dependency unit. Intensive Care Nurs 7:171-178

Salyer J, Stuart BJ (1985) Nurse-patient interaction in the intensive care unit. Heart Lung 14:20-24

Sarvimäki A (1988) Nursing care as a moral, practical, communicative and creative activity. J Adv Nurs 13:462-467

Scheiner R, Knipfer E (2006) Miteinander reden: Wege zu einer gelingenden Kommunikation in der Pflege. Pflege Z 59:Suppl. 2-8

Schiereck S (2000) Soziale Interaktion zwischen Pflegekräften und PatientInnen im Organisationsverlauf einer Nursing Development Unit. Pflege 13:234-241

Schröck R (2003) Interaktionen zwischen Pflegenden und Patienten Eine klassische Studie in der akuten Psychiatrie. Pflege 16:17-25

Shattell M (2004) Nurse-patient interaction: a review of the literature. J Clin Nurs 13:714-722

Sheldon LK, Barrett R, Ellington L (2006) Difficult communication in nursing. J Nurs Scholarsh 38:141-147

Smith-Stoner M (1999) Language - as important as documentation! Home Healthc Nurse 17:350-352

Spiers JA (2002) The interpersonal contexts of negotiating care in home care nurse-patient interactions. Qual Health Res 12:10331057

Sumner J (2001) Caring in nursing: a different interpretation. J Adv Nurs 35:926-932

Tacke D (1999) Pflege von Menschen mit Aphasie - Eine Literaturstudie. Pflege 12:95-100

Tuckett AG (2005) The care encounter: pondering caring, honest communication and control. Int J Nurs Pract 11:77-84

Tuckett AG (2007) Stepping across the line: information sharing, truth telling, and the role of the personal carer in the Australian nursing home. Qual Health Res 17:489-500
Turnock C (1991) Communicating with patients in ICU. Nurs Stand 5:38-40

Usher K, Monkley D (2001) Effective communication in an intensive care setting: nurses' stories. Contemp Nurse 10:91-101

van Maanen H (2002) Die Entwicklung einer Pflegefachsprache aus einer pflegewissenschaftlichen Perspektive: Das Warum und Wozu. Pflege 15:198-207

Vivian BG, Wilcox JR (2000) Compliance communication in home health care: a mutually reciprocal process. Qual Health Res 10:103-116

Walther S (2003) Sprache und Kommunikation in der Pflege. Forschungsarbeiten und Publikationen zur mündlichen und schriftlichen Kommunikation in der Pflege: Eine kommentierte Bibliographie. Gilles und Francke, Duisburg

Watson J (2005) Commentary on Shattell M (2004) Nurse-patient interaction: a review of the literature. Journal of Clinical Nursing 13:714-722 J Clin Nurs 14:530-532

Westin L, Danielson E (2007) Encounters in Swedish nursing homes: a hermeneutic study of residents' experiences. J Adv Nurs 60:172-180

Wikström BM (2003) Health professionals' experience of paintings as a conversation instrument: a communication strategy at a nursing home in Sweden. Appl Nurs Res 16:184-188

Williams A (2001) A literature review on the concept of intimacy in nursing. J Adv Nurs 33:660-667

Williams CA, Gossett MT (2001) Nursing communication - advocacy for the patient or physician? Clin Nurs Res 10:332-340

Williams KN, Ilten TB, Bower H (2005a) Meeting communication needs: topics of talk in the nursing home. J Psychosoc Nurs Ment Health Serv 43:38-45

Williams K, Kemper S, Hummert ML (2005b) Enhancing communication with older adults: overcoming elderspeak. J Psychosoc Nurs Ment Health Serv 43:12-16 